\title{
Correction to: Directed Repeats Co-occur with Few Short-Dispersed Repeats in Plastid Genome of a Spikemoss, Selaginella vardei (Selaginellaceae, Lycopodiopsida)
}

Hong-Rui Zhang ${ }^{1,2}$, Xian-Chun Zhang ${ }^{1}$ and Qiao-Ping Xiang ${ }^{1 *}$

\section{Correction to: BMC Genomics (2019) 20:484 \\ https://doi.org/10.1186/s12864-019-5843-6}

Following the publication of this article [1], the authors reported that the Fig. 2 described in the article had a mistake that two grey blocks in S. moellendorffii was not placed as background color, and in the Fig. 2 legend, chlL-chlN was wrongly written into $\operatorname{chl} l \mathrm{~L}-c h l \mathrm{~L}$. They have therefore provided the following alternative Fig. 2 in this Correction article in order to show the accurate information.

\section{Author details}

${ }^{1}$ State Key Laboratory of Systematic and Evolutionary Botany, Institute of Botany, the Chinese Academy of Sciences, Beijing 100093, China. ${ }^{2}$ University of Chinese Academy of Sciences, Beijing 100049, China.

Received: 20 June 2019 Accepted: 20 June 2019

Published online: 26 June 2019

\section{Reference}

1. Zhang $H-R$, Zhang X-C, Xiang Q-P. Directed repeats co-occur with few short-dispersed repeats in plastid genome of a Spikemoss, Selaginella vardei (Selaginellaceae, Lycopodiopsida). BMC Genomics. 2019;20:484 https://doi. org/10.1186/s12864-019-5843-6.

\footnotetext{
* Correspondence: qpxiang@ibcas.ac.cn

${ }^{1}$ State Key Laboratory of Systematic and Evolutionary Botany, Institute of

Botany, the Chinese Academy of Sciences, Beijing 100093, China

Full list of author information is available at the end of the article
}

(c) The Author(s). 2019 Open Access This article is distributed under the terms of the Creative Commons Attribution 4.0 International License (http://creativecommons.org/licenses/by/4.0/), which permits unrestricted use, distribution, and reproduction in any medium, provided you give appropriate credit to the original author(s) and the source, provide a link to the Creative Commons license, and indicate if changes were made. The Creative Commons Public Domain Dedication waiver (http://creativecommons.org/publicdomain/zero/1.0/) applies to the data made available in this article, unless otherwise stated. 


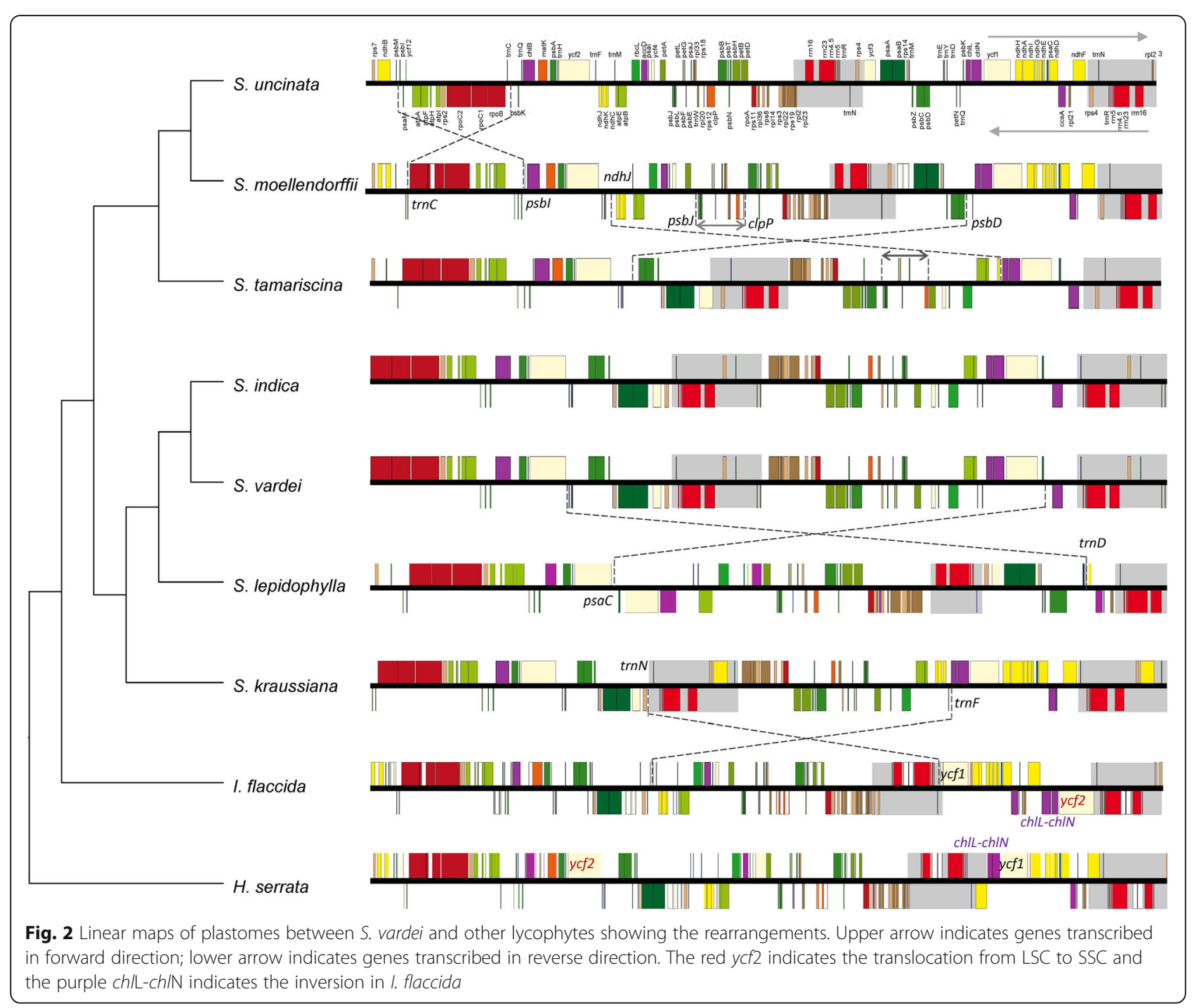

